\title{
Mooren's Pseudoulcer Revealing Chronic Atrophic Polychondritis
}

\section{Biram Codou Fall*, El hadji Daouda Niang, Assane Sall, Amadou Fall Cisse, Ahmadou Gaye, Aly Salane, Aichetou Fall, Bamba Diaw and Souhaibou Ndongo}

Department of Internal Medicine, CHN Dalal Jamm, Senegal

*Corresponding Author: Biram Codou Fall, Department of Internal Medicine, CHN

Dalal Jamm, Senegal.
Received: December 10, 2021

Published: December 20, 2021

(C) All rights are reserved by Biram Codou

Fall., et al.

\begin{abstract}
Introduction: Atrophying polychondritis is a rare auto-immune disease characterized by recurrent episodes of inflammation of cartilage tissue. Ocular involvement may occur in 60-70\% of cases. Moreen's pseudo-ulcer is a rare complication. It is serious because of the visual prognosis. We report a case of Mooren's pseudo-ulcer revealing atrophic polychondritis.

Observation: A 49 year old female patient, followed in ophthalmology for a pain in the left eye associated with chemosis, lacrimation, photophobia and a decrease of visual acuity in the right eye. The ophthalmological examination showed a superinfected pseudo Mooren's ulcer of the right eye on slit lamp examination. She consulted dermatology for an irritative dermatitis of the feet. She was referred to internal medicine for an opinion on an inflammatory auricular swelling. On examination, she presented a chronic polychondritis with (Chondritis of the right ear with atrophy, nasal chondritis without «saddle» or «marmite feet» deformity, chondro-costal chondritis) without hypoacusis, without vestibular syndrome; a chronic peripheral polyarthritis, and not deforming. Biology showed a moderate chronic inflammatory syndrome. Immunological investigations were negative. Cardiovascular and respiratory function tests are in progress. The diagnosis of chronic atrophic polychondritis was retained in the presence of 2 major and 1 minor criteria according to the Michet criteria and the presence of 4 out of 6 criteria according to the McAdam criteria. A treatment based on methylprednisone and Azathioprine was prescribed. The patients showed good progress under treatment with improvement of polyarthritis, polychondritis and ocular inflammation.

Conclusion: Atrophying polychondritis is a rare autoimmune disease with a recurrent and sometimes severe course. Ocular involvement is usual during the course of the disease and can be inaugural as shown in this observation. The présence of a Mooren's pseudo-ulcer should be investigated for this etiology.
\end{abstract}

Keywords: Chronic Atrophying Polychondritis; Pseudo Mooren; Africa

\section{Introduction}

Chronic Atrophying polychondritis (CAP) is a rare connective tissue disease, evolving through repeated episodes of inflammation, mainly affecting the cartilaginous structures of the ears, nose and tracheobronchial tree [1]. It is potentially serious and incapacitating due to systemic damage (cardiovascular, pulmonary, hematological, cochleovestibular, and ocular articular). Ocular involvement (60 to $70 \%$ of cases) is predominantly episcleritis, scleritis and more rarely choroiditis and keratitis [2].
Mooren's ulcer is a rare form of peripheral corneal ulceration related to autoimmunity against a corneal stromal antigen. Systemic diseases can be complicated by immunologic peripheral keratitis, which is referred to as Mooren's pseudo-ulcer. In the absence of a specific marker, the diagnosis of CAP is primarily clinical. Very rare observations have been reported in Africa [3]. We report a case of atrophic polychondritis with a pseudo-Mooren's ulcer as the mode of revelation which evolved well under treatment. 


\section{Case Présentation}

A 49 year old female patient, followed in ophthalmology for a pain in the left eye associated with chemosis, lacrimation, photophobia and a decrease in visual acuity in the right eye. The ophthalmological examination showed a right episcleritis. At the corneal level, a fluorescein-positive deepening ulcer with infiltration of the corneal stroma was found by slit lamp, suggestive of a superinfected Mooren's ulcer of the right eye (Figure 1). Local corticosteroid therapy was initiated by her ophthalmologist after management of the superinfection. She consulted dermatology for an irritative dermatitis on her feet. She was referred to internal medicine for an opinion on an inflammatory right auricular swelling (Figure 2). On examination, she presented with chronic polychondritis with right auricular chondritis with atrophy without hypoacusis or vestibular syndrome, nasal chondritis without «saddle» or «marmite foot» deformity; chronic peripheral polyarthritis (shoulders, elbows and knees) without deformity Biology showed a moderate chronic inflammatory syndrome. Immunological investigations were negative. Cardiovascular and respiratory function tests were normal. The diagnosis of chronic atrophic polychondritis was retained in the presence of 2 major and 1 minor criterion according to the criteria of Michet., et al. and the presence of 4 out of 6 criteria according to the criteria of Mc Adam., et al. A treatment based on prednisone at $1 \mathrm{mg} / \mathrm{kg} / \mathrm{d}$ with progressive decrease and Azathioprine $100 \mathrm{mg} / \mathrm{d}$ was prescribed. The patient progressed well under treatment, with improvement of the polyarthritis, polychondritis and ocular inflammation (Figure 3).

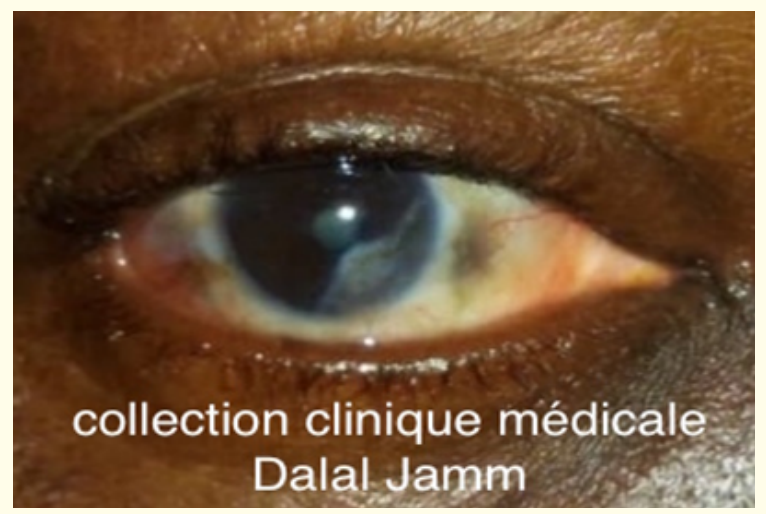

Figure 1: A peripheral whitish inflammatory infiltrate without a healthy corneal interval between the limbal vascular arch and this infiltrate in the right eye.

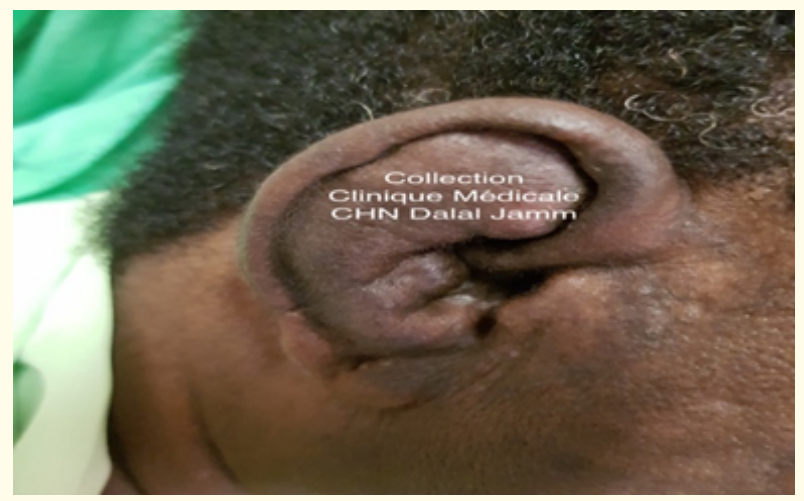

Figure 2: Right auricular inflammatory tumor

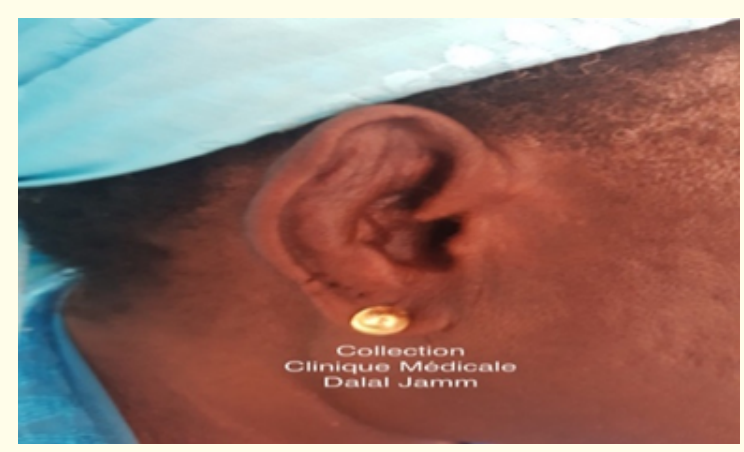

Figure 3: Good evolution of auricular chondritis after treatment

\section{Discussion}

CAP was first described in 1923 by Jaksch-Wartenhorst as «polychondropathy»; the term «recurrent polychondritis» was introduced by Pearson., et al. in 1960, to emphasize the particular intermittent course observed in 12 patients [4].

Its prevalence has been estimated in the United States to be between 3.5 and 4.5 per million inhabitants, while in a recent Hungarian epidemiological study it was 20 per million [5]. The disease can occur at any age, but the average age of the first symptoms is around 40-45 years [1]. Very rare cases have been reported in Africa, reflecting a lack of awareness rather than our socioeconomic context [3]. 
Ocular involvement is rare and occurs in $60 \%$ of cases [2]. Episcleritis (39\%) and scleritis (14\%) are the most common manifestations, followed by cataract (11\%), keratoconjunctivitis sicca (10\%), and other possible conditions include iritis, retinopathy, keratitis, optic neuritis and corneal melting. Inflammation external to the globe may result in orbital pseudotumor and should be discussed as Wegener's granulomatosis with polyangiitis, a condition in which it is more common. In our patient, the ocular involvement was revealing of the disease. It presented as a right episcleritis with a Mooren's ulcer on the cornea. Wood and Kaufman [6] classified Mooren's ulcer into two groups: Type I was benign, usually unilateral with mild to moderate symptoms, occurring in older people (over 35 years of age) and generally responding well to medical and surgical treatment. In contrast, type II was more often bilateral, more painful with usually a poor response to therapy. It occurs in younger patients (under 35 years of age) and is known as malignant Mooren's ulcer. A Chinese series found that the mean age of the first ocular manifestation of Mooren's ulcer was 48.4 years and $79.5 \%$ of patients were over 35 years of age with a male predominance. Mooren's ulcer was predominantly an adult disease. Peripheral corneal ulcers in some autoimmune diseases may be similar in all respects to Mooren's ulcer and are referred to as Mooren's pseudo-ulcer [7].

Our case reports a unilateral Mooren's ulcer occurring from the age of 45 years. The female predominance of Mooren's pseudo-ulcer associated with CAP, as shown in the case reported by Ouédraogo., et al. [7], is explained by the clear female predominance of CAP.

Peripheral corneal ulcers in certain autoimmune diseases may be similar in every respect to Mooren's ulcer; this is referred to as Mooren's pseudo-ulcer [7].

Unilateral or more frequently bilateral atrial chondritis is the most common feature of CAP, which is seen in up to $90 \%$ of patients during the course of the disease, and is the inaugural symptom in $43 \%$ of cases [2]. After several episodes, cartilage atrophy may sometimes appear with a «cocker's ear» or «cauliflower» appearance [8]. Hypoacusis is observed in about $37 \%$ of CAP [2]. It is thought to be related to cochlear damage and the mechanism of this damage may be mixed: cases of vascular damage have been described but also autoimmune deafness with the presence of anti-labyrinth antibodies [8].
Conductive hearing loss is also possible with various mechanisms: stenosis of the external auditory canal, serous otitis possibly secondary to chondritis of the eustachian tube. A vestibular syndrome could be associated with cochlear damage or occur in isolation [9]. Nasal chondritis occurs in about $60 \%$ of patients and is characterized by a painful inflammation of the nasal cartilage septum, often accompanied by rhinitis or epistaxis, which evolves into nasal ensellurement in 17 to $29 \%$ of patients [2,9]. An auricular chondritis should rule out an infectious or traumatic cause, whereas a nasal ensellurement is primarily a cause for discussion of granulomatosis with polyangiitis, which may be associated with it, but also syphilis and leprosy. Laryngeal-tracheal-bronchial involvement is observed at presentation in only $10 \%$ of cases, but it eventually develops in half of the patients [10]. It should be evoked in front of a pain in front of the thyroid or tracheal cartilage; dysphonia, cough, dyspnea, stridor or weezing Repeated attacks can lead to severe laryngotracheomalacia, which is the main cause of mortality [11]. Arthritis is the second most common symptom of CAP and ultimately affects more than $70 \%$ of patients. Arthritis in pure recurrent polychondritis is intermittent, migratory, asymmetric, seronegative, and usually non-erosive [12]. Recurrent polychondritis is often described in the presence of other arthropathy-inducing diseases such as connective tissue diseases, rheumatoid arthritis and spondyloarthropathies [8]. Inflammatory spinal pain and para-articular manifestations (tendonitis, tenosynovitis) are common. However, all cartilaginous structures can be affected (sterno-costals, chondro-costals, symphysis pubis...).

Cardiovascular involvement is observed in 6 to 30\% of cases, dominated by aortic insufficiency (10\%) often secondary to dilatation of the ascending portion of the thoracic aorta [11]. In our patient, no cardiovascular manifestations were noted at the time of diagnosis.

Mucocutaneous manifestations are reported in 37\% of cases and mainly concern forms associated with myelodysplasia [13]. The lesions are diverse and not very specific, predominantly oral aphthosis followed by erythema nodosum (15\%), purpura, pustules and livedo. The MAGIC syndrome (mouth and genital ulcers with inflammed cartiages) is a form of overlap between CAP and Behcet's disease. In our patient an irritative dermatitis was found without myelodysplasia. Other involvement may be renal (22\%) associated with a higher incidence of extrarenal vasculitis, arthri- 
tis and poorer survival; neurological (3\%) with a higher frequency of cranial nerve involvement, but convulsions, headache, cerebral aneurysm and rhomboencephalitis have been described [2].

A biological inflammatory syndrome usually accompanies relapses, but its absence should not lead to a rejection of the diagnosis. However, to date, there is no validated biological marker specific to CAP. Our patient presented with a biological inflammatory syndrome indicating disease activity [9].

In the absence of a specific marker, the diagnosis of CAP is primarily clinical. The classification criteria for CAD of Michet., et al. [11] require: the presence of evidence of inflammation in at least two of the three ear cartilages, nasal cartilage or laryngotracheal cartilage, or evidence of inflammation in one cartilage plus two other signs, including ocular inflammation, vestibular dysfunction, seronegative arthritis or hearing loss. There are also the criteria of McAdam., et al. proposed in 1976 [11] and subsequently modified by Damian and Levine [14].

The prognosis of patients with CAP is variable and depends on organ involvement and response to treatment. In a recent series of 142 patients, the factors associated with decreased survival were: male gender, cardiac involvement, and the presence of one or more hemophilia [8].

In our patient, the prognosis seems good because the CAP is not deforming and there is no other visceral damage besides Mooren's pseudo-ulcer.

In the absence of prospective studies, the treatment of CAP is not codified and must be discussed on a case by case basis. In some minor forms with only episodic chondritis of the pinna, the use of nonsteroidal anti-inflammatory drugs, colchicine, or short corticosteroid therapy in flare-ups is sometimes sufficient [8]. Immunosuppressive drugs and surgical conjunctival resections find their indications in severe forms. Dapsone, initially described as a promising treatment, is less and less used. Immunosuppressants including cyclophosphamide, azathioprine, mycophenolate mofetil and methotrexate are used initially in severe respiratory or vascular forms or secondarily in cases of corticosteroid resistance or dependence [15]. The management of Mooren's pseudo-ulcer is based on local corticosteroid therapy in combination with systemic corticosteroid therapy if the response is not satisfactory or if the causative condition justifies it [16]. In our patient, we used a combination of local and oral corticosteroids and azathioprine as background treatment. The therapeutic response was satisfactory with regression of polychondritis and ocular involvement. The 10-year survival rate reported in a series from 1986 was 55\%; whereas in 1998 , another series revealed that $94 \%$ of patients were alive after 8 years, testifying to the major progress in management, which still remains problematic [15].

\section{Conclusion}

Atrophying polychondritis is a rare autoimmune disease with a recurrent and sometimes severe course. Ocular involvement is usual during the course of the disease and may be Inaugural as shown in this observation. The presence of a Mooren's ulcer should be investigated.

\section{Bibliography}

1. Mathew SD., et al. "Relapsing Polychondritis in the Department of Defense Population and Review of the Literature". Seminars in Arthritis and Rheumatism 42.1 (2012): 70-83.

2. Lahmer T., et al. "Relapsing polychondritis: An autoimmune disease with many faces". Autoimmune Review 9.8 (2010): 540-546.

3. Gning SB., et al. "Polychondrite atrophiante associée à un adénocarcinome rectal et une fibromatose musculoaponévrotique chez une Africaine”. La Revue de Médecine Interne 22.9 (2001): 891-893.

4. Pearson CM., et al. "Relapsing Polychondritis". The New England Journal of Medicine 263.2 (1960): 51-58.

5. Horvath A., et al. "A nationwide study of the epidemiology of relapsing polychondritis". Clinical Epidemiology 8 (2016): 211-230.

6. Wood TO and Kaufman HE. "Mooren's Ulcer". American Journal of Ophthalmology 71.1 (1971): 417-422.

7. Ouedraogo N., et al. "Pseudo-ulcère de Mooren révélant une polychondrite atrophiante". La Revue de Médecine Interne 39 (2018): A224.

8. Dion J., et al. "Polychondrite atrophiante : actualités en 2017". La Revue de Médecine Interne 39.6 (2018): 400-407. 
9. Dion J., et al. "Relapsing Polychondritis Can Be Characterized by Three Different Clinical Phenotypes: Analysis of a Recent Series of 142 Patients: RP can be divided into three clinical phenotypes". Arthritis Rheumatology 68.12 (2016): 2992-3001.

10. Chang S-J., et al. "Laryngotracheal Involvement as the Initial Manifestation of Relapsing Polychondritis". Journal of the Chinese Medical Association 68.6 (2005): 279-282.

11. McAdam LP., et al. "Relapsing polychondritis: prospective study of 23 patients and a review of the literature". Medicine (Baltimore) 55.3 (1976): 193-215.

12. Jawad AS., et al. "Erosive arthritis in relapsing polychondritis". Postgraduate Medical Journal 66.779 (1990): 768-770.

13. Francès C., et al. "Dermatologic Manifestations of Relapsing Polychondritis: A Study of 200 Cases at a Single Center". Medicine (Baltimore) 80.3 (2001): 173-179.

14. Damiani JM and Levine HL. "Relapsing polychondritis--report of ten cases". The Laryngoscope 89 (1979): 929-946.

15. Trentham DE. "Relapsing Polychondritis". Annals of Internal Medicine 129.2 (1998): 114.

16. Watson PG. "Management of Mooren's ulceration". Eye 11.3 (1997): 349-356.

\section{Assets from publication with us}

- Prompt Acknowledgement after receiving the article

- Thorough Double blinded peer review

- Rapid Publication

- Issue of Publication Certificate

- High visibility of your Published work

Website: www.actascientific.com/

Submit Article: www.actascientific.com/submission.php

Email us: editor@actascientific.com

Contact us: +919182824667 